\title{
Governar pelas Normas ${ }^{1}$
}

\author{
Government by Norms
}

\section{Laurent Thévenot}

École des Hautes Etudes en Sciences Sociales, Paris, França

\section{Tradução de Daniela Velásquez Peláez}

\section{Daniela Velásquez Peláez}

Programa de Pós-Graduação em Antropologia, Universidade Federal Fluminense, Niterói, Rio de Janeiro, Brasil

\section{RESUMO}

Para dar conta de uma forma de governança fundamentada nos standards de qualidade e, mais geralmente, da política da informação formal, Laurent Thévenot reconsidera as noções de norma e de informação. A maneira na qual é regulamentada a qualidade e na qual são fixados os standards excede a distinção habitual entre as normas sociais, standards técnicos e normas de verdade. $\mathrm{O}$ autor diferencia os tipos de normalização em função dos "formatos de informação", que são, eles mesmos, relacionados a diversos regimes de envolvimento e a diversas formas de coordenação. Se origina assim um fundamento novo para criticar a standarização.

Palavras-chave: Normalização, Regimes de envolvimento, Standarização.

1 [N.T.] Uma versão deste artigo foi publicada originalmente em: Un gouvernement par les normes: Pratiques et politiques des formats d'information. In: CONEIN, B.; THEVENOT, L. (ed.). Cognition et information en société. Paris: Les Éditions de l'EHESS, 1997. p. 205-241. (Raisons Pratiques 8). O artigo original foi editado e atualizado pelo autor especificamente para este volume, contando com recursos provenientes dos projetos: Projeto Cep 29: Núcleo capixaba de estudos da experiência humana em meio urbano (EDITAL CNPq/FAPES No 22/2018 - PROGRAMA PRIMEIROS PROJETOS - PPP, nº 058/2019), coordenado por Manuela Blanc; e Projeto Rede Internacional de Pesquisa sobre administração de conflitos em espaços públicos plurais: desigualdades, justiças e cidadanias em perspectiva comparada, coordenado por Fabio Reis Mota (EDITAL CAPES/PRINT - n 41/2017, vinculado ao Instituto de Estudos Comparados em Administração de Conflitos - InEAC e ao Programa de Pós-Graduação em Antropologia- PPGA da Universidade Federal Fluminense). 


\section{ABSTRACT}

To account for a form of government embedded on quality standards and, more generally, formal information politics, Laurent Thévenot reconsiders the notions of norm and information. The way in which quality and standards are regulated and fixated exceeds the usual distinction between social norms, standard techniques and true norms. The author distinguishes different types of normality according to "information forms", which are, themselves, related to different engagement regimes and coordination approaches. It is originated then a new ground for criticizing standardization.

Keywords: Normalization, Engagement regimes, Standardization.

Qual é o tipo de política que compreende o amplo movimento de normalização pelo qual fomos envolvidos? Podemos falar em "política" ao seu respeito, tratá-lo para além da técnica ou da economia que emergem das normas que governam as coisas? Essas questões manterão aqui a nossa atenção em detrimento das três ordens de desafios que elas comportam.

É a amplitude do fenômeno que surpreende em primeiro lugar. O movimento de normalização, acentuado na construção do mercado europeu, transborda amplamente dos domínios técnicos e profissionais especializados. Sua extensão é visível sob o olhar de todos à medida que cresce a lista dos seres de nosso entorno que se submetem às normas europeias - ele vai das áreas de jogo onde as crianças se divertem até as cercas que alinham os campos e configuram as paisagens. Seu alcance político é ao menos perceptível nas reações de agricultores ou de pequenos empreendedores às novas limitações das suas atividades que são atribuídas ao peso de uma autoridade designada como "Europeia". Qual é então a natureza deste "mercado das normas" (THÉVENOT, 1995a)? Para responder a esses questionamentos, esclarecer a política das normas e viabilizar a sua avaliação crítica, se faz necessário examinar de perto os dispositivos que produzem as referências normativas.

A economia política de mercado, uma rara construção política integrante das coisas, encontra a questão da normalização. No entanto, ela tende a não conhecer mais que o comércio das coisas no seu estado de mercadorias e utilidades. O estudo da normalização deve armar-se de instrumentos menos específicos no sentido do mercado e abrir-se à variedade de "normalidades" que regem os envolvimentos num entorno de seres humanizados, de natureza e de artificio.

Foi para dar conta dessas normalidades variadas que nós desenvolvemos um quadro de análise que distingue os "regimes de envolvimento" segundo as conveniências ou as convenções que os governam. Aplicado à normalização, esse desenvolvimento evidencia particular- 
mente um desafio: reelaborar a noção de informação para elucidar suas ligações com a norma. A operação de "compreensão" das coisas e das pessoas que nós situamos no centro dos regimes de envolvimento, é reveladora destes vínculos. Compreender é, em efeito, envolver numa atividade, mas também é apreender pelo conhecimento dos pontos de referência informativos. A compreensão compõe a informação em diversos "formatos": do indício perceptivo de um gesto a um marcador convencional. Ela obriga a situar a noção de informação em relação a duas outras questões: a sua transformação numa questão comum² nas coordenações e nas figuras do coletivo; e sua incorporação numa atividade que lhe coloca a prova. As duas relações da informação, com o coletivo e a prática, são particularmente visíveis na norma, em razão do seu reconhecimento coletivo e da sua força prescritiva sobre os modos do fazer. Seu estudo requer um deslocamento das noções de informação ou de cognição para sair das categorias de uma psicologia mentalista e alocá-las na coletividade e nos envolvimentos práticos que dela fazem parte. É pela sua abertura nessas questões que as Ciências Sociais podem, sem dúvida, aportar suas maiores contribuições à análise da informação e do conhecimento (THÉVENOT, 1998) e orientar os estudos sobre a cognição por diversos e peculiares caminhos.

Depois de uma apresentação do quadro de análise que nós desenvolvemos para relacionar diversos formatos de informação aos diferentes envolvimentos pragmáticos, uma primeira parte deste artigo utiliza esse quadro para examinar os diferentes lugares onde reside a normatividade das normas: lugares de promulgação que suscitam críticas e justificação sobre a escolha de marcadores formais, mas também lugares para a construção de relações das normas com o mundo real onde se exerce um policiamento das coisas ${ }^{3}$ que as submete à questão para que suas propriedades lhes sejam extraídas. $\mathrm{O}$ quadro proposto resulta atento às implicações morais ou

\footnotetext{
2 [N.T.] Em conjunto com o autor e com o revisor, buscamos uma tradução mais apropriada para o verbo frasal "mettre en commun" do francês que desse conta de exprimir o seu lugar no âmbito da sociologia pragmática desenvolvida a partir do trabalho do autor e de outros cientistas sociais de outros países. Sobretudo, acentuando a dimensão processual das relações sociais, com os objetos abordados e dos modos de coordenação da ação presentes na atividade de convenção e qualificação das pessoas e dos objetos. Contudo, ao longo das discussões chegamos à conclusão da necessidade de expressar de forma mais direta o seu sentido, pois ele é vital para a construção teórica proposta no artigo. Sendo assim, acordamos que a sua substituição por "transformar numa questão comum" seria mais adequada, pois "mettre en commun", como utilizado neste contexto, faz referência ao ato da mobilização de uma questão pessoal que, quando comunicada, adquire o estado e o status de um lugar comum. Como, ao contar uma história, a compartilhamos com outros acionando um conjunto de sensações e referências, que, ora, remete ao seu conteúdo particular daquele que conta a história contagiando a quem a ouve, ora mobilizando sentimentos e transformando a história em algo que, mais que compartilhado, é comungado por aqueles que são tocados, mobilizados, e inscritos nos fios da história e em suas nuances.

3 [N.T.] O sentido da palavra policiamento, neste contexto remete a uma vigilância constante e não necessariamente a uma ação dos operadores da segurança pública. Remete assim ao ato ou sentido de policiar-se, conforme utilizado no português.
} 
políticas da compreensão dos objetos, das formas de objetividade e de realismo. A segunda parte trata das políticas de informação formalizada (por meio da classificação, dos códigos e dos instrumentos de medida) e se abre a uma confrontação com outras aproximações do fenômeno, que se interessam pelas implicações políticas de uma cognição em sociedade. Na terceira parte, nós observaremos a extensão da normalização dos bens às pessoas, com o estabelecimento de novos sistemas de normalização de competências elementares: referindo-se a uma "sociedade cognitiva”, eles participam da elaboração de uma nova grandeza de informação. Um recuo saudável, necessário para a análise destas construções políticas de base cognitiva, supõe uma abertura crítica à pluralidade dos formatos de informação.

\section{FORMATOS DE INFORMAÇÃO CONVENIENTES AOS DIFERENTES ENVOLVIMENTOS PRAGMÁTICOS}

As Ciências Sociais contribuem para o preenchimento de lacunas de reflexão acerca da natureza de uma informação formal; elas chamam a atenção às diversas âncoras dos modos do conhecimento e ao trabalho necessário de desconectar a informação da situação. O programa que nós desenvolvemos encontra sua origem numa investigação sobre a fabricação e utilização da informação formal. A compreensão que compõe a informação foi inicialmente abordada pela cadeia estatística e informática, a qual posteriormente foi ampliada a partir dos investimentos de forma que sustentam as coordenações gerais. Nos interessamos pelas maneiras formatar os seres e os eventos com a finalidade de constituir modos de conhecimento propensos a serem abstratos às coisas, às pessoas e às situações, a serem generalizados e circulados. Em lugar de tomar por certa a solidez das formas coletivas de objetividade social ou, ao contrário, de colocá-la em questão para o aproveitamento de uma negociação local ou de uma indexação, relacionamos a diversidade das formatações informativas às diferentes possibilidades de coordenação.

A informação não está vinculada nem aos coletivos objetivantes, nem aos indivíduos conhecedores, mas sim a uma coordenação problemática. Esta orientação leva a uma preocupação pela concreção da informação, pelo lugar do suporte material que contribui ao seu realismo. Esta abordagem acentua a pluralidade das formas do provável que servem ao julgamento (THÉVENOT, 1992). Uma vez relacionados os investimentos de forma aos modos de coordenação, nos resta nos interrogarmos sobre sua validade desigual: a noção da informação encontra aqui a noção de legitimidade. A formatação utilizável pelas avaliações do bem comum é uma 
qualificação segundo uma ordem de grandeza e responde às exigências de justificação pública (BOLTANSKI; THÉVENOT, 1991).

Uma vez reconhecido que a noção corrente de "informação" depende de julgamentos públicos que governam as coordenações de grande porte, considerei outras modalidades de coordenação em ambientes mais restritos assentados numa variedade de formas de informação, das mais gerais e legítimas às referências mais localizadas e personalizadas, relacionando-as a uma pluralidade de regimes de envolvimento do ser humano no seu ambiente, o envolvimento sendo caracterizado por uma conveniência que governa as apreciações trazidas pela pessoa na sua conduta e na dinâmica de ajustamento mobilizadas por ela (THÉVENOT, 1990b). À medida que nos afastamos dos regimes que se aproximam da formalização dos modos de conhecimento, para ir em direção aos envolvimentos de proximidade, a informação perde a sua exterioridade formal e se ancora nas referências perceptivas depositadas no curso de uma familiarização com o ambiente. As referências não podem ser explícitas, transformadas em questões comuns e nem comunicadas da mesma forma.

Os envolvimentos são apreendidos do ponto de vista dos seres humanos, ainda se a "agência" humana difere de um regime para o outro: o ser convencionalmente qualificado se distingue do indivíduo projetado (planificado) ou da pessoa familiarmente envolvida com seu ambiente. É do ponto de vista do ser humano que se pode identificar uma normalidade ou uma normatividade, entendidas num sentido mais amplo que aquele coberto pela noção de norma social e das relações com as formas de apreciação dos desenganos numa prova de realidade. A diferença de noções de ação, de prática ou de rotina, o envolvimento é caracterizado tanto pela agência humana quanto pela maneira pela qual é compreendido o ambiente envolvente. Assim, o regime de envolvimento da projeção ${ }^{4}$ - também nomeado de regime de envolvimento no

\footnotetext{
4 [N.T] Em outras traduções do autor, tal como a do artigo "Reconhecimentos: com Paul Ricoeur e Axel Honneth" publicada no número 44 da Antropolítica, se faz referência ao regime de envolvimento no plano como tradução padrão do "régime d'engagement en plan". É necessário um trabalho de maior precisão para melhor dimensionarmos o sentido atribuído ao conceito no artigo e na obra do autor. Para tanto, proponho, nesta versão, utilização do termo regime de envolvimento da projeção, no lugar de regime de envolvimento no plano. "Plano" no Brasil significa traçar certas estratégias visando lograr êxito e prevendo as condições de desenvolvimento das diferentes etapas envolvidas no plano. Contudo, se no régime d'engagement en plan são previstas as dimensões imprevisíveis próprias da coordenação das ações humanas, embora se suponha a possibilidade de conformar instrumentos cognitivos e pragmáticos sustentados pelo manto da previsibilidade. Tanto o plano, como a antecipação, são recursos que no Brasil não estão necessariamente disponíveis nos aparelhos da vida cotidiana ou mesmo das normas, leis, procedimentos burocráticos, administrativos e do mercado envolvidos na circulação dos dispositivos de ação apresentados aqui pelo autor. Portanto, numa adaptação terminológica que exprime o sentido trazido pelo autor, a projeção como uma maneira de construção dos planos para o futuro, concede um melhor revestimento do sentido atribuído ao conceito.
} 
plano - repousa não somente na individualização de um agente a quem é atribuída uma agência intencional planificadora, mas igualmente sobre a contrapartida oferecida por um ambiente de objetos compreendidos pelas suas funcionalidades.

A partir dessa conceitualização dos modos de coordenação segundo os regimes de envolvimento, a construção proposta responde ao problema de compreender, num mesmo quadro, a conduta de pessoas em coletividade, a ação individualizada ou as relações ao próximo ou ao familiar. A noção de envolvimento faz ressurgir as normatividades elementares que governam as relações com o mundo e ajuda a identificar os diferentes lugares de normatividade do dispositivo de normalização, para depois elucidar os sentimentos de abuso de poder que eles suscitam e que provém de tensões críticas entre formas de envolvimento.

\section{O lugar da normatividade das normas}

Qual normatividade está contida nas normas e onde ela reside? Colocada tão abruptamente, a questão parece abranger a sua própria resposta. As normas não são necessariamente construídas para serem instrumentos de normatividade? Elas não fixam objetivos, procedimentos de verificação de cumprimento e de sanções? A resposta simples, que segue a definição ideal mais oficial do dispositivo de normalização, não exaure a questão. O dispositivo contém uma pluralidade de lugares de normatividade que buscamos identificar. Para fazê-lo, é necessário explorar diferentes normatividades sem reduzi-las a um modelo único de normas sociais que funcionam como alicerces dos grupos sociais. Devemos manter-nos atentos, ao contrário, às diversas normalidades implicadas nas relações com as coisas e com as diferentes figuras do coletivo nas quais o comércio com as coisas encontra lugar.

Se nós relacionamos as referências informativas aos modos de envolvimento que elas garantem, a informação se inscreve de imediato numa ideia de normatividade que não está mais isolada ou reservada a uma noção de valor, e sim inscrita no quadro de apreciação daquilo que convém. Em certos regimes, o quadro avaliativo se afasta consideravelmente da noção de valor por se aproximar a um objetivo mais limitado, fechando-se no sucesso de uma ação de projeção ou de um acomodamento familiar. Uma vez especificado um regime de convenções coletivas que servem para coordenar as condutas em relação às ordens de justificação, o estudo da normalização não a reduz à identificação do gênero de convenção que sustenta a norma? Em efeito, a decomposição do dispositivo mostra que a normalização está longe de se reduzir a apenas um regime de convenções coletivas justificáveis. A pesquisa sobre as normas de segurança, que será explorada mais adiante, mostra que o mecanismo de normalização funciona na conjunção de diversos regimes e formatos de informação, tal análise lança uma nova luz sobre as tensões 
internas aos processos, suas transformações históricas e suas implicações políticas.

\section{Justificação e normalização}

Comecemos por observar a norma nos seus momentos de crítica e justificação pública, enquanto a validade da referência normativa é questionada assim como os controles que ela supõe e nos quais ela deve relacionar-se com convenções coletivas. A referência convencional está inscrita numa argumentação e as justificações legítimas que aludem ao bem comum são convocadas quando associadas à emergência de causas críticas.

\section{Normalização e qualificação industrial}

A normalização das coisas ou dos métodos é particularmente propícia a uma qualificação de grandeza industrial como nós, eu e Luc Boltanski, o reconhecemos ao estudar esta ordem (BOLTANSKI; THÉVENOT, 1991). Os seres são postos em série segundo critérios formais propícios à abstração da medida e ao seu transporte. As análises empíricas confirmaram que nas colocações a prova operadas segundo essa grandeza (a industrial), as normas são inevitavelmente convocadas em situações tão diferentes quanto na fabricação de um produto alimentício com denominação de origem (THÉVENOT, 1989), na obtenção de um crédito num banco popular (WISSLER, 1989), num conselho de classe (DEROUET, 1992), na mobília pedagógica (NORMAND, 1997), e no desenvolvimento de um ambiente natural (LAFAYE; THÉVENOT, 1993; MORAND, 1997; THÉVENOT, 1996a).

$\mathrm{Na}$ história da normalização, as justificações de ordem de grandeza industrial foram as primeiras, posto que tratam da estandardização para assegurar o aumento da eficácia, para evitar a incompatibilidade entre equipamentos e métodos, ou diminuir a divergência no uso de produtos fabricáveis - divergência esta que injustificável aos olhos de quem os utiliza na sua funcionalidade normal. A normalização foi, num começo, problema dos manufatureiros que procuravam economias de variedade e permutabilidade de produtos em virtude da uniformização de tipos. A literatura econômica recente consagrada à normalização é focada na difusão e adoção de standards de compatibilidade, ainda quando as modelizações propostas são estendidas à dinâmica das normas sociais (DAVID, 1994).

Quais são os instrumentos de medida para as diferentes ordens de qualificação?

A análise aprofundada dos casos mencionados anteriormente mostra que as normas técnicas são frequentemente utilizadas nos julgamentos que vão para além da justificação industrial para se orientar em direção de uma outra grandeza, seja ela doméstica (agroalimentar, ban- 
co popular), cívica (estabelecimento escolar) ou mesmo verde (projeto de planejamento de um parque natural). Em alguns casos concretos, se busca a correspondência entre os compromissos e a compatibilidade local entre diversas ordens de justificação pesquisadas, como no aparelho escolar de educação nacional, o qual repousa amplamente num compromisso cívico-industrial (DEROUET, 1992).

Entretanto, em outras situações, os instrumentos apropriados para a prova de grandeza industrial são convocados para sustentar uma causa que se justifica de outras maneiras. Em lugar de um compromisso, trata-se de um recurso instrumental para uma forma de prova não congruente com a grandeza que se pretende principal. Assim, os ecologistas podem constituir um dossiê tomando emprestado o tipo de aparelhagem de prova industrial que os planificadores industriais utilizam para sustentar o projeto de desenvolvimento contra o qual estão lutando. As provas de grandeza não industrial usam normas, mas normas de outro gênero: sociais (costumeiras na ordem domestica), jurídicas (na ordem cívica). Essas últimas não permitem a medida pela aparelhagem que está no cerne do dispositivo contemporâneo da normalização. Em todos esses casos, é possível observar que as qualificações diversas recorrem, instrumentalmente, a uma prova de ordem industrial.

\section{Qualidades mercantilizáveis}

Entre as convenções próprias da ordem mercantil, a moeda vem imediatamente em mente, já que é, por excelência, a medida comum das avaliações de preço e norma. Mas não se deve esquecer das convenções requeridas para consolidar os suportes dessa avaliação monetária: os bens em si mesmos. A identificação comum dos bens constitui um pilar da pretensão de justiça nas relações mercantis, é normal que uma longa história de tratamento da qualidade das mercadorias seja acompanhada da expansão dos mercados. Longe da crença economista na naturalidade de um tratamento das coisas no estado de mercadoria, as sociedades humanas têm construído este artifício moral, esta "qualidade moral" no senso de Pufendorf, com o fim de poder segurar nela os julgamentos. Para não ser demasiado vago ou se orientar demais pelas convenções sociais, a "construção social dos mercados" deve ser compreendida ao lado das convenções mercantis, a diversidade de convenções que dão suporte à identidade dos bens. Sob acordos coletivos do regime de justificação, se verá, na próxima seção, o lugar das convenções ou conveniências mais limitadas e localizadas contribuintes ao policiamento das mercadorias.

Dos standards comerciais de marcas às próteses normalizadoras do mercado

A extensão do mercado não acontece tão espontaneamente quanto a teoria econômica 
dos mercados concorrentes ou as tabelas sobre a inevitável globalização do comércio tendem a fazer acreditar. Ela é acompanhada de todo um equipamento de artefatos técnicos e convencionais que não são simplesmente implementações de dispositivos de qualificação mercantil. Esse equipamento conduz a especificar a fórmula de Polanyi de um mercado "incrustado", e a distinguir os acontecimentos de mercados histórica e culturalmente situados apontando às tensões críticas que cada um esconde.

As empresas já contribuem a uma internacionalização e a uma estandardização de fato, graças ao equipamento das marcas. A sinalização das marcas e a materialização do reconhecimento (logos, ícones normalizados, marcas registradas, rótulos e denominações controladas) não conhecem seu desenvolvimento pleno a não ser pela condição de serem sustentadas não só pelos lugares de mercado, como também por um imponente dispositivo de visibilidade e difusão da ordem do renome. A transposição de marcas de empresas para além dos limites da arena mercantil instaura uma qualificação pelo reconhecimento na opinião que não se encontra inscrita na ordem mercantil. Elencada na sua lógica própria, essa qualificação não é verdadeiramente aberta a uma prova de concorrência e tende verdadeiramente a uma uniformização que de fato prejudica a variedade no mercado de produtos. É uma tal uniformização que é procurada pelo processo de "massificação" e, atualmente, da "macdonalização". Nas tipologias das normas, esta estandardização "de fato" se opõe às estandardizações "de lei”, apelando aos regulamentos. A designação da norma "de fato" é, não obstante, errônea se tomarmos como medida o aparelho industrial de uniformização e de controle disponibilizado pela empresa, a qual duplica o dispositivo de compromisso de marketing orientado ao mercado e à opinião. Quanto à normalização “de lei”, ela se aproxima da gestão contratual de marcas com a transformação progressiva de uma normalização regulamentada pelo Estado numa normalização "voluntária".

Este tipo de normalização contratual ocupa um lugar central na internacionalização dos mercados e na construção europeia. A autoridade de Estado no policiamento das mercadorias, em parte, se reporta a um dispositivo contratual governado pelas normas de qualidade. Em resultado, um composto de liberalismo e de normalização metrológica. A fórmula mesmo deste "liberalismo normalizador" indica que ele contém fortes tensões internas. Opacado pela cobertura técnica, esse movimento tem grande abrangência. Ele modifica a maneira de conceber os objetos técnicos na sua valoração econômica, recompõe as figuras clássicas do produtor e do consumidor, alterando até mesmo as concepções políticas de cidadania, os modos de intervenção e as formas adequadas de governança. 
Normas para os direitos cívicos: do consumidor ao cidadão

As justificações que modelam o dispositivo de normalização não correspondem apenas a uma ordem industrial ou mercantil, elas também podem se ancorar numa ordem cívica na medida em que visam a proteção dos direitos de cidadãos. A partir de uma racionalização da engenharia, da política de mercado, a normalização amplia sua vocação para responder não somente aos agenciamentos de produtores, de vendedores e compradores, mas também de consumidores ou cidadãos que fogem das qualificações industrial e mercantil. É possível observar isso em termos das normas de segurança dos produtos, ou das normas ambientais e agroambientais. Tal como no caso do direito do trabalho -desenvolvido para remediar as assimetrias de poder em que a figura contratual de um acordo de vontades é ignorada -, o direito do consumidor foi desenvolvido para corrigir a desigualdade do contrato mercantil com o produtor (KESSOUS, 1997). Ao se desvincular pouco a pouco da política do mercado e da repressão de fraudes a proteção se estende aos riscos de utilização (Lei de 1978), depois à segurança e à saúde dentro do quadro de uma "proteção do consumidor" (Lei de 1983) (idem). Esta orientação cívica foi inicialmente levada em consideração pelos serviços públicos, no prolongamento de uma metrologia de Estado, até o momento em que a normalização regulamentaria foi questionada em nome do imperativo mercantil da concorrência. As diretivas europeias favoreceram enormemente a substituição de regulamentos de Estado pelos procedimentos de regulamentação que participam de uma chamada cadeia de conformação voluntária e que obrigam a uma formalização da informação ao longo da corrente certificadora.

\section{O POLICIAMENTO DAS COISAS: DA NORMA À PROVA}

As diferentes justificações dos processos de normalização podem ser vistas em espaços propícios para a argumentação pública, entre eles os comitês de normalização, onde os parâmetros e métodos são inscritos no texto da norma. Nesses espaços, os julgamentos e provas são então submetidos à exigência de uma qualificação geral. Apesar disso, grande parte da maquinaria de normalização se dedica à aplicação das normas: operações de medida que colocam à prova para julgar a conformidade de uma coisa. Essas operações nos levam em direção a outros lugares e a outros tipos de normatividade que não estão mais governados por um regime de justificação. Longe das convenções coletivas, a apreciação da conformidade é sustentada pelas conveniências do envolvimento na projeção numa ação normal, ou ainda pelo envolvimento 
familiar numa ação habitual, nas quais estão implicados os acomodamentos familiares dos experimentadores professionais ou usuários.

A pesquisa mostra que as medidas de conformidade às normas não podem ser limitadas ao regime ao qual o cientista adere nas suas publicações, e nem visam compreender completamente as coisas a partir das suas propriedades físico-químicas relacionando seu comportamento às leis (THÉVENOT, 1993a). A política da segurança é uma quadratura das coisas mais desajeitada: ela deve integrar as utilizações "razoavelmente previsíveis" de uma coisa, que não necessariamente se ajustam às leis científicas. No quadro da natureza finalmente produzida pelo laboratório científico, a agência humana deve desaparecer. Na normalização dos bens, pelo contrário, é impossível ignorar os envolvimentos de tal agência humana no uso da coisa.

Os agenciamentos do indivíduo e do objeto

Se Marx desmontou o "fetichismo da mercadoria" ao nos ensinar a reconhecer o "valor de uso", a pesquisa deve prolongar-se via uma investigação sobre uma outra espécie de fetichismo, aquele da utilidade, que envolve também as "relações sociais". O valor de uso permanece infelizmente naturalizado na oposição ao valor de mercado, ainda mesmo que o termo "valor" deva indicar uma avaliação comum e incitar a pesquisar as convenções coletivas que a sustentam. O que pode ser que ilumine essa questão é seguir uma política da segurança dos objetos que não se restrinja ao valor convencional mercantil, mas que estenda o seu alcance a uma compreensão funcional do envolvimento na projeção e, ainda, vá além de certas variações idiossincráticas do uso do envolvimento familiar. A compreensão dos efeitos da normalização não deve limitar-se a uma uniformização social frequentemente denunciada porque o indivíduo não teria mais lugar ali. A normalização funcional é, em efeito, congruente com uma individualização da agência humana.

\section{A redução dos envolvimentos funcionais e familiares com as propriedades do objeto}

A normalização orientada por um imperativo de segurança comporta assim tensões internas que precisam ser evidenciadas com a finalidade de conduzir uma análise crítica. A qual supõe a compreensão do objeto nos diversos envolvimentos da transação de mercado e a observação das diferentes agências do comprador e do vendedor. Da mesma maneira que os estudos sobre o trabalho reivindicam o lado do intercâmbio contratual que considera um domínio tanto do envolvimento na projeção quanto a habilidade do envolvimento familiar. Do mesmo modo o problema da utilização obriga ao aprendizado dos usos nas experiências da compra, todas elas distintas. O imperativo de segurança demanda que o objeto seja colocado à prova na utilização, 
e o horizonte do acidente convida a ir além do funcionamento normal para observar os usos desviantes. A consideração dos usos acomodados, familiares ou mesmo exploratórios, deve, portanto, resultar numa qualificação do produto que seja propícia à entrada no mercado. A maquinaria do teste transforma, assim, os envolvimentos funcionais para a projeção de uma ação "normal", ou as acomodações pessoais na familiaridade em propriedades dos objetos, podendo passar pelas extensões de propriedades físico-químicas.

Um meio maior de transformação consiste, para o técnico de normalização, em prolongar o trabalho de ajustamento e, inspirado pelo seu colega metrologista, construa até mesmo protótipos para o ser humano. Bem entendido, o ajustamento de protótipos é imponente para operar a redução perfeita de um regime de envolvimento a outro: não se pode compreender a agência humana relevando o regime de envolvimento na projeção com a ajuda das propriedades intrínsecas do objeto envolvido. Na melhor das hipóteses, os suplentes da ação serão aprendidos a partir de regularidades comportamentais integradas no teste. No teste de um porta-bebês, por exemplo, o suporte é submetido a agitações regulares de cima a abaixo que simulam os sobressaltos ocasionados pelo caminhar do ser humano que carrega o bebê.

A redução parece ser melhor sucedida do que o ajustamento de protótipos, pois a última se relaciona em si mesma às propriedades físico-químicas fundamentais que a fizeram objeto de uma metrologia científica. Assim, o bebê que ocupa a ação de deglutição é colocado em propriedade a partir de uma boca-padrão, reduzida a um gabarito que tem a forma mais pura de um cilindro oco cujo fundo é inclinado num ângulo de $45^{\circ}$, e sobre as dimensões acordadas pelos membros da comissão de normalização (documento CENT/TC 252/WG 3, N104 do 22/12/1993). Com a redução do bebê a essas propriedades físicas elementares, parece ser possível conter as ações humanas que levam a diferentes regimes de envolvimento que diferem na sua compreensão do mundo envolvente. Ainda reduzido a propriedades elementares, o protótipo pode ainda trazer estigmas de uma ação humana anterior. O ajustamento do protótipo da mão humana que segura o berço e que está integrada no teste de "estabilidade longitudinal" se concretiza num tubo de diâmetro de $10 \mathrm{~mm} / 80 \mathrm{~mm}$ (idem N104). Um técnico denuncia que essa escolha se deveu "ao tubo que eles tinham em mãos" no laboratório onde inicialmente haviam preparado o teste ao qual ajustaram a norma posteriormente. Num outro caso é denunciado o agente humano, sob o argumento de que no teste foi tomado "o ferro angular que havia à vista e foi ele que entrou na norma ainda que hoje não seja possível encontra-lo" (técnico de laboratório de ensaio). 
A agência humana no transporte das propriedades

Estranhamente, as normas têm a pretensão de evitar a aporia da regra, incluindo as regras na sua própria aplicação. Sem ter lido Wittgenstein, Kripke ou Goodman, sem se lembrar da regressão infinita dos "instrumentos judicatórios" aos quais Montagne se refere, os normalizadores de campo sabem, pela experiência, que a regra da regra não parará a "roleta" infinita, segundo os termos de Montaigne. Os técnicos encarregados da prática das normas, nos laboratórios de Estado ou nas empresas privadas, falam sem parar de "elaborar", "assegurar", "manter", "uma interpretação": "quando existe a norma, existe um texto, uma lei, mas há também uma interpretação" (técnico de segurança de uma empresa). Esse vocabulário de interpretação, todo apontando à colocação em prática da regra, arrisca de parar a reflexão sobre um tipo de fascinação frente ao abismo interpretativo que explorou intensivamente o movimento pós-moderno. É insuficiente para precisar o tipo de envolvimento sobre o qual repousam as convenções.

Um técnico de empresa encarregado das questões de padronização é então obrigado a manter as propriedades pagando por elas pessoalmente e, se assim se pode dizer, pelo seu produto, e a manter a "interpretação comum” da norma através de ações e acomodações locais. Para preparar um teste efetuado por um laboratório britânico num produto francês, ele se transporta com seu produto antes da elaboração de uma interpretação comum da aplicação da norma a um novo objeto. A "negociação" que se segue tem lugar depois de cada grande inovação mas opera na base das referências estabelecidas no momento de "interpretações" anteriores. No caso de uma reorganização administrativa que levou a uma mobilidade significativa do pessoal de um laboratório britânico, o estabelecimento da interpretação nos envolvimentos familiares foi destruído e as referências de acomodamento devem ser fixadas novamente nos lugares, em pessoa e em coisa:

Conheci uma personagem nova. É isso que é interessante no âmbito das normas, o approach da pessoa: como ela responde a suas perguntas, como elas serão interpretadas, como elas são situadas em nível de conhecimento. Para os novos, o terreno é virgem. Eu tinha feito contatos, feito certas interpretações com a pessoa anterior. Aquilo que eu quero, é que aquilo que adquiri possa ser transportado à nova pessoa, todas as minhas anotações etc. [...]. No âmbito dos ensaios de estabilidade, o posicionamento do manequim no carrinho de bebê, nós não damos a norma de como prendê-lo. Para os carrinhos de passeio, no limite, isso pode fazer com que eles tombem. Isso coloca um problema de transferência com o novo. Para o novo carrinho, eu já havia negociado interpretações. Fazê-lo aceitar não era evidente porque não tinha toda essa anterioridade. (técnico de segurança da empresa). 


\section{Políticas da informação normalizada}

Depois de identificar os diferentes tipos de normatividade que se ocultam no seio do dispositivo de normalização, nós estamos melhor equipados para tratar das implicações políticas da adaptação e colocação das normas. Nosso quadro de análise é propício a esse exame, pois ele trata das formas elementares de envolvimento das pessoas, bem como das construções políticas e morais do acordo e do desacordo. Centraremos a nossa atenção nas modalidades de composição de diferentes formatos de informação e nas consequências de uma redução dentre as quais opera uma "emergência da política". A investigação sobre a normalização se abre enquanto uma reflexão mais ampla sobre a política da informação formalizada que prolonga um programa anterior sobre a política das estatísticas (DESROSIÈRES, 1993; THÉVENOT, 1990a, 1994a). Enquanto ela transborda dos universos professionais, técnicos e econômicos, para imiscuir-se em todos os lugares da nossa vida cotidiana, a informação formalizada suscita as tensões com outros modos de informação e de conhecimento pertinentes nas relações com o mundo que não estão submetidas às mesmas exigências de governança pública. A análise crítica da normalização não saberá então parar na uniformização que implica a estandardização. Ela deverá se interessar pelas consequências das operações de formalização em outros formatos de informação e pelos envolvimentos que os sustentam. Ao mesmo tempo que ela estende o propósito à informação normalizada, esta segunda parte se abre a uma confrontação com outras abordagens sociológicas dos fenômenos de normalização da informação, que nos interessam porque eles chamam a atenção para suas implicações políticas.

\section{OS REPRESENTANTES EM QUESTÃO: DELEGADOS, MINORIAS E ENVOLVIMENTOS MÚLTIPLOS NAS CONVENÇÕES}

Uma modalidade importante da politização dos temas estudados aqui gira em torno da questão dos representantes e da representação. Bruno Latour e Michel Callon colocaram essa noção no centro da sua construção sociológica original. Seu mundo é povoado por representantes, delegados, tenentes. Apesar dessas personagens e das intrigas nas quais eles se involucram em ocasiões controversas, esta sociologia não se interessa pelas condições da discussão, da crítica ou até mesmo da negociação aberta entre porta-vozes. Ela se ocupa, numa concepção diferente das relações políticas, da maneira pela qual os arranjos de fazem e se desfazem, de fato. O principal questionamento diz respeito à força do representante, em consonância com a refle- 
xão política e semiológica que Hobbes consagrou àquele que autoriza e assinala a autoridade. A revelação das pretensões do representante, que se encontra em outras sociologias como a de Pierre Bourdieu, consiste então em revelar a rede de interesses em cujo extremo o porta-voz não saberia desvincular-se como um tenente de suas tropas. O encadeamento das redes transborda a delegação humana em razão do papel atribuído aos actantes não humanos que dele participam e que desempenham, também, o ofício de delegados (CALLON; LAW, 1989).

A metrologia ilustra perfeitamente estas configurações em rede, nas quais os representantes de unidade da medida científica se prolongam em múltiplas ramificações. É por isso que Latour se interessa por isso desde cedo, preocupado por trazer à luz as correntes de seres humanos e os instrumentos que contribuem para a extensão da ciência ao mundo (LATOUR, 1995). Assinalamos que o caso da metrologia difere de outros campos estudados pela sociologia do ator-rede, nos quais é a rede que detém o representante, e os nódulos de controvérsia ou tradução são revelados pelo trabalho do sociólogo ainda se a última opção opera seguindo os atores. No caso da metrologia, a rede é reconhecida e valorizada pelos mesmos atores. Procedendo de uma "traçabilidade" que permite a reconstituição, elo por elo, da identidade do objeto, ele oferece periodicamente o espetáculo de colocar a prova cada um dos seus elos. Essa diferença, entre uma rede de referência para os atores e uma rede revelada pelo pesquisador como rendimento da sua pesquisa, é significativa se cuidamos da maneira na qual os atores tratam e apreciam seus envolvimentos: benefícios das redes que transportam e consolidam um valor de referência numa reputação, uma metrologia ou uma traçabilidade; delitos de um poder que transborda da capacidade normal e provoca uma dependência da qual gostaríamos de nos desprendermos.

\section{Crítica a uma sociologia de delegados e política de minorias}

A sociologia dos porta-vozes oscila entre a pintura de uma base agitada, no auge das controvérsias, e a constatação desiludida da inelutável condenação ao silêncio dos porta-vozes fora desses momentos. As críticas são levantadas contra essa segunda posição e contra a política subjacente que só dá a palavra aos grandes portadores privilegiados. Friedberg (1993, p. 207) escreve assim:

A saída de Callon e Latour vem a seguir exclusivamente o pensamento do ou dos tradutores (do ou dos inovadores) em detrimento de todos os outros atores. Ela demanda que nos coloquemos unicamente no lugar do ou dos tradutores, em lugar de se colocar sucessivamente na posição de todos os atores preocupados pela reconstituição do sistema de relações que os vincula.

Suzan Leigh Star se atentam à mesma questão em suas pesquisas sobre o assunto abor- 
dado aqui: normas de informação inscritas nas classificações internacionais (Bowker e Star, 1997) e convenções (STAR, 1991). Ela demanda que a voz seja devolvida aos atores alinhados sob o representante e aos deixados por conta das convenções. Nesse debate, nós daremos atenção à transferência entre modelos sociológicos e modelos sociais e políticos.

A crítica de Star se une ao liberalismo político em sua relutância à delegação coletiva que uniformiza e aos standards que ignoram as diferenças entre os indivíduos. Nos motivos de desconfiança ao olhar das delegações e traduções, o argumento, não obstante, se afasta do liberalismo. O caso em questão é um standard de mercado que não é uma norma decretada de lei e sim uma norma de fato: proveniente de uma política privada de empresas, um produto se generaliza a partir da implementação multinacional e de imitações que asseguram ao standard sua cobertura mundial. Star (1991) não estabelece a vinculação simples entre o liberalismo político e o liberalismo econômico que apresenta rotineiramente o laissez-faire do segundo como o protetor da liberdade individual defendida pelo primeiro. Ela denuncia que o hambúrguer padrão não lhe convém, pois tem alergia a cebola. A diferença entre indivíduos é vista como desigualdade de acesso e, longe de uma desvantagem de natureza, a desigualdade é tematizada como a lacuna entre uma minoria e uma maioria que constitui a base do standard. A falta de poder de compra de um grupo de interesse particular ("special needs") composto por pessoas alérgicas a cebola, não cria um "nicho de mercado" que tenha como objetivo um novo standard sem cebolas. A ilustração mostra que a prova do mercado não é adequada para regulamentar a qualificação de um produto que é aqui em parte cívico, pois ela deve prevenir um risco de saúde ou compensar uma deficiência. Mais do que olhar para esse componente cívico comum às normas de saúde ou segurança, Star (1991) circunscreve a questão numa política de defensa das minorias. Essa política comporta elementos cívicos na denúncia de desigualdades entre maiorias e minorias, mas igualmente toma emprestada, das figuras políticas de inspiração liberal, a valoração de uma composição multicultural da coisa pública.

A "política da identidade" à qual Star (1991) se refere não se limita a um pleito multicultural que apoia novas convenções fundamentadas nos pertencimentos minoritários. O múltiplo não é apenas configurado no nível da sociedade, uma pluralidade liberal de indivíduos ou num multiculturalismo de grupos identitários, mas figura no nível da pessoa a partir do tema da "personalidade múltipla" que retorna positivamente. Ao invés de que um espaço público seja composto a partir de uma confrontação liberal de escolhas identitárias, é a personalidade mesma que é presentada como resultado de uma negociação entre as personalidades múltiplas anexadas a mundos diferentes. A passagem de uma figura à outra é favorecida pelo modelo sociológico utilizado: a dos "objetos fronteira" negociados em razão do seu pertencimento simultâneo a 
vários mundos sociais (STAR; GRIESEMER, 1989). A representação, no envolvimento dos atores, se opõe ao pertencimento múltiplo a mundos diferentes que dá lugar à negociação de identidades pessoais.

\section{O peso das convenções sobre as pessoas}

A aproximação de Star (1991) aporta então à análise crítica das normas e convenções. Ela reencontra a crítica de John Law (1994) na constatação de que a coordenação assegurada pelas convenções é relativa e só se realiza no preço da exclusão e da desordem para as pessoas e as situações que não se prestam a elas: se o "McDo 5 " standard ordena, em quaisquer instantes cotidianos, o mundo de uma clientela imponente, inúmeros são os excluídos que padecem do desconforto e do caos (STAR, 1991). Star propõe então que nos interessemos numa "fenomenologia dos encontros com as convenções e as formas estandardizadas" com a finalidade de explorar a "distribuição do convencional"(ibid, p. 42) e de colocar em evidência as pessoas que carregam a carga dessa distribuição e da manutenção da estandardização. Essa orientação sugere levar em consideração a "natureza do pessoal" no cerne das redes, cuja ausência é deplorada na teoria ator-rede pelo contraste com sua colocação nas pesquisas feministas, as quais desvelam o trabalho doméstico que remanesce invisível nas economias. A política da identidade desenhada por Star (1991) faz da pessoa o nódulo de múltiplas ligações compostas de pertencimentos a diversos mundos sociais diferentes. Podemos então tratar melhor da fenomenologia das convenções recorrendo a uma noção de mundo social que é, ela mesma, apreendida em termos da convenção de Howard Becker (1988)?

As observações de Star (1991) têm um porte que ultrapassa os modelos de porta-voz revelando o avesso das convenções de coordenação. Para aprofundar-se nas questões suscitadas, com Luc Boltanski, nós mesmos tomamos como objeto as tensões críticas que provocam as operações de "formatação de equivalência" e de ganhar generalidade. Distinguir a pertinência daquilo que é legítimo generalizar, opondo-se àquilo que retorna ao particular ou à contingencia, não é apenas uma operação cognitiva, essa distinção participa de um julgamento que apela às figuras do bem comum. À medida que vai sendo alcançado, o estabelecimento das categorias, das classificações e das normas que constituem as informações de âmbito geral, resulta em reações críticas e resistências. Nós observamos essa dinâmica crítica operando no interior

5 [N.T.] Na França, o apelido para a popular rede de comidas rápidas.

6 [N.T.] No original "mise en equivalence". Vale notar que, embora seja utilizada a tradução "formatação de equivalência", é fundamental perceber a ênfase no processo, no movimento de dar forma à equivalência e a potencial transformação derivada deste movimento. 
de uma ordem de justificação (por exemplo, entre as demandas que tem um peso no mercado e aquelas que não possuem um "nicho"), ou entre as diferentes ordens (por exemplo, entre uma estandardização justificada por um mercado e uma normalização justificada pela segurança dos cidadãos). Com os desenvolvimentos ulteriores obrando sobre uma ampla gama de regimes de envolvimento, nós analisamos outras fontes de tensão crítica, entre regimes de argumentação pública e regimes de envolvimento pessoal. A análise dessas tensões críticas entre regimes de envolvimento permite compreender os sentimentos de abuso de poder suscitados pela redução a convenções coletivas.

\section{Redes compostas e envolvimentos múltiplos}

A análise de Star encontra lugar nas figuras políticas decentralizadas que são congruentes com diferentes sociologias que acentuam os conhecimentos distribuídos. As convergências aparecem assim nos Estados Unidos, entre as abordagens da teoria "ator-rede" (desenvolvida por Latour e Callon), as pesquisas sobre a inteligência "distribuída" erguidas contra os modelos do programa e do plano (GASSER, 1991), os trabalhos sobre os artefatos informacionais (NORMAN, 1993), os modelos de conhecimentos distribuídos (HUTCHINS, 1994) e as pesquisas anteriores sobre cognição distribuída (CICOUREL, 1974, 1990). Contra as hierarquias, os planos e as capacidades individuais são valorados os vínculos locais, as relações com equipamentos de cooperação e as dinâmicas emergentes.

As dimensões da rede ou da distribuição arriscam, por um achatamento operado na figura de um gráfico, sugerir uma homogeneização dos vínculos que asseguram a circulação de um meio e de apagar, pela sua conectividade, as tensões críticas que nos preocupam. Enquanto é reconhecida a heterogeneidade dos diversos segmentos, a análise dos nódulos se torna crucial para compreender as condições de composição (conjunção ou combinação) de segmentos dispares. As noções de "tradutor" ou "mediador", mais do que explicar, apontam em direção das limitações e possibilidades de um trabalho de composição requerido para que transite qualquer capacidade a despeito dos diversos vínculos. Assim, a transitividade de contatos pessoais tem como objetivo o transporte da confiança nos julgamentos sobre a competência dos salariados (EYMARD-DUVERNAY; MARCHAL, 1997) requerendo, sem dúvida, regimes diferentes daqueles implícitos nos vínculos pessoais: a construção do julgamento de terceiros, auxiliada pelos dispositivos que consolidam essas redes, e a qualificação de pessoas de confiança ou de coisas penhoráveis segundo as formas de reputação que contribuem à generalização da confiança depositada no próximo.

Não são apenas os vínculos entre pessoas, mas também as relações com as coisas que 
devem ser compreendidos na sua diversidade. A ideia de uma delegação de um propósito às coisas, extremamente frutífera pela maneira que ela revela seu lugar nas coordenações humanas, aporta o risco de compreendê-las apenas no seu formato funcional, negligenciando seu acomodamento no uso. Abrindo a investigação sobre as modalidades variadas do comércio com as coisas (THÉVENOT, 1994), situamos um lugar para um envolvimento na projeção e um tratamento disciplinante pela função, em relação aos usos que só aparecem, sob a observação deste regime da projeção, como desvios ou deslizes em relação a uma normalidade instrumental.

\section{A COMPREENSÃO DAS COISAS: POLÍTICAS DA MEDIDA}

Enquanto os objetos compreendidos são de uso cotidiano, a normalização dos mesmos suscita tensões particularmente vivas entre diferentes maneiras de compreensão. Sendo assim, a multiplicidade de modos de compreensão sobre os objetos difere, em grande medida, das suas implicações na normalização metrológica, posto que serão reduzidos às suas propriedades científicas e, portanto, abstraídos de qualquer outra compreensão humana? A metrologia encontra, em efeito, problemas semelhantes, mais notáveis à luz dos trabalhos sobre a normalização de objetos cotidianos que incitam à emergência de uma variedade de regimes de envolvimento implicados. Mallard (1996, p. 384) revela a noção oficial, na abordagem metrológica, de "valor convencionalmente verdadeiro". Os próprios metrologistas explicitam o acordo convencional no qual reside o valor da verdade, sem a necessidade de sociólogos das ciências prontos para encontrar o papel das intervenções humanas no universo secreto dos laboratórios que produzem as leis universais. A convenção pública coletiva é erigida no regime de envolvimento da projeção: a convenção, conforme colocado no texto de normalização, deriva a sua tolerância de uma “diferença pouco significativa para o objetivo colocado" no seio da organização.

\section{Paralelo com a compreensão metrológica das propriedades}

Para normalizar as medidas e manter as "propriedades físicas essenciais" que são favorecidas pelo técnico de ensaios, o próprio metrologista é levado a extrair as propriedades físicas de situações e de objetos materiais cuja manipulação revela regimes de envolvimento bem diferentes. Esses objetos híbridos são, ao mesmo tempo, envolvidos na projeção a partir da sua funcionalidade e, na qualidade de protótipos, portadores de propriedades físicas fundamentais. Assim como os técnicos que arrancam os olhos dos ursinhos de pelúcia, aqueles que estão en- 
carregados da medição da voltagem devem viajar pessoalmente, cultivar laços de proximidade com seus colegas para estabelecer envolvimentos familiares e proximidade com os equipamentos em uso. A pluralidade de formatos de informação e dos envolvimentos implicados desaparece em cada prestação de contas. Joseph O'Connell se alinha a outros sociólogos das ciências (Latour, Collins, Shaffer) para desmascarar, na metrologia, o trabalho invisível dos técnicos que mantém em prática a universalidade da ciência, trabalho que eventualmente é apagado da imagem na exposição científica. Essa revelação contribui à causa de representantes oferecendo bons motivos para denunciar o abuso de poder de um grupo social de sábios e a divisão social do trabalho que os acompanha. O deslocamento que propomos para seguir a nossa investigação preliminar coloca em evidência a redução de uma pluralidade de regimes de envolvimento que resulta na dominação de apenas um entre todos os outros.

Os repetidos esforços pela desvinculação de regimes incompatíveis através do tratamento das propriedades físico-químicas ecoam em toda a história da metrologia. Discutindo o ajustamento de um protótipo de uma resistência elétrica em meados do século XIX, os britânicos contestaram a unidade proposta pelo industrial alemão Siemens porque ela dependia de materiais (mercúrio) e de construções (uma coluna de $1 \mathrm{~mm}$ de perfil e $1 \mathrm{~m}$ de altura a $0^{\circ} \mathrm{c}$ ) julgados arbitrários. O ideal é referir-se a "unidades primárias" (massa, largura, tempo) "carimbados com o selo da autoridade, não do legislador ou do homem de ciência, e sim da natureza" (Relatório de 1873 apud O’Connel, 1993).

\section{Da normalização dos bens à normalização das pessoas: a formação de uma cité informacional}

Uma abordagem informacional da atividade humana

As implicações políticas do movimento de normalização de bens são mais visíveis enquanto o movimento se estende à qualidade dos seres humanos, medidos em termos de "competências profissionais de base”. Há aproximadamente uma década, foi elaborada, no Reino Unido, uma nova forma de compreender as competências segundo as National Vocational Qualifications ${ }^{7}$, com o objetivo de servir tanto à gestão de empregos quanto à de formações. Havendo inspirado sistemas análogos em outros países do Commonwealth (Austrália, África do Sul), da ALENA (México), ou do antigo bloco do Leste liberalizado, esse movimento encontrou eco recentemente na França pelo canal de recomendações europeias retomadas no âmbito nacional. A lógica do sistema de normalização de competências, e em particular os seus desvios em re-

7 [N.T.] Qualificações vocacionais nacionais, em inglês no original. 
lação às formas mais antigas de classificação e qualificação profissional, só é compreensível se partirmos do desvio tomado em direção à normalização de produtos, a qual serviu de modelo para a normalização das competências. A transferência das capacidades de trabalho de toda a maquinaria desenvolvida para gerar os bens e serviços a partir da certificação da sua qualidade é facilitada pela qualificação intermediária de serviços, que não saberiam estar completamente desvinculados da atividade dos seres humanos (DE BANDT; GADREY, 1994).

Estes novos standards de competência de inspiração liberal visam alinhar tanto quanto possível os mercados de trabalho ao mercado de produtos e lutar contra as "rigidezes" que provêm da articulação dos ofícios, dos aprendizados e dos diplomas. As novas formas de qualidade estabelecidas em termos de competência não integram mais, na apreciação das pessoas e nas suas colocações à prova, os vínculos duráveis às formas instituídas de coletivos: sejam sindicatos de categorias ou empresas. Enquanto as figuras do coletivo de grandeza doméstica ou cívica dotam o agente de um pertencimento segundo diferentes construções de comunidade, o seu questionamento é apresentado como a liberação dos pertencimentos denunciados, numa avaliação puramente mercantil, dos obstáculos de um mercado das qualidades. No novo sistema, a "liberdade" corresponde principalmente à figura de um sujeito individual contratante, nesse caso, em consonância com um mercado de trabalho e com uma empresa. O objetivo é de compreender as capacidades que são simultaneamente elementares e gerais, cujas combinações múltiplas permitem a reconstrução fiel das qualificações das vagas de emprego, bem como os contornos de formação e as aptidões das pessoas. Esta problemática da redução às qualidades elementares é semelhante àquela do economista de mercado que decompõe cada bem num compêndio de características que supostamente esgotam a sua qualidade global. Embora, como observamos com relação ao produto, a decomposição desfaz o regime de troca mercantil para se encaminhar às propriedades que devem ser compreendidas de outra forma.

\section{A normalização das qualidades numa "sociedade cognitiva"}

Das “superestradas de informação" à "sociedade de informação", a noção de informação conhece hoje um uso bastante extenso que manifesta as capacidades de relacionar e de valorar as atividades humanas e seus equipamentos, podendo considerar-se a gestação de uma nova grandeza e uma nova cité da "informação", da mesma maneira que é possível identificar uma "grandeza verde" em curso de elaboração. A noção de informação se insinua na apreciação das mais diversas situações cotidianas e na avaliação da competência das pessoas. As argumenta-

ções de grande porte se sustentam nos equipamentos próprios às técnicas de informação, da informática às mídias, se referindo a um bem comum propenso a beneficiá-los a todos. Assim, 
se elabora uma nova forma de justificação que repousa numa comum dignidade a ser informada numa prova de comunicação. Diferentemente da grandeza de opinião, que é provada pelos sinais de reconhecimento, a grandeza da informação repousa numa formalização daquilo que informa. É por isso que a normalização ocupa um lugar central no equipamento dessa grandeza.

O Livro branco sobre educação e formação (1995) produzido pela Comissão Europeia inclui o subtítulo "em direção à sociedade cognitiva". Ele afirma que no momento em que sejam inseridos e situados os "mapas pessoais de competências" participando de um "sistema de acreditação das competências" a nível europeu, "será tomado um grande passo em direção à sociedade cognitiva". As recomendações propostas valoram uma nova relação com o mundo, uma “"relação cognitiva' [que] estruturará cada vez mais as nossas sociedades” pois "o futuro da União Europeia, a sua irradiação, serão possíveis em grande parte devido à sua capacidade de acompanhar o movimento em direção à sociedade cognitiva" (COMISSÃO EUROPEIA, 1995, p. 5). As recomendações do Livro branco desenham os contornos de um dispositivo que classifica a compreensão das competências individuais num duplo equipamento metrológico e jurídico: "Também se faz necessário fazer com que o nível de competência atingido por cada um seja um instrumento de performance individual, cuja definição e uso garantam a mais possível igualdade dos direitos dos trabalhadores" (ibidem).

\section{CONCLUSÃO: OS INSTRUMENTOS DE UMA ABERTURA CRÍTICA SOBRE OS FORMATOS DA INFORMAÇÃO}

Se afirmando cada vez mais como um quadro geral do comércio dos seres humanos, entre eles e com o ambiente onde se encontram, a certificação das qualidades normalizadas tende a substituir outros vínculos mais abertamente políticos. Uma regulação erguida sobre as propriedades objetivas instaura um modo de governança no qual se desloca o debate político em direção aos princípios de avaliação das propriedades dos objetos e na procedimentalização dos lugares de debate e julgamento da sua qualidade. A amplitude desse policiamento das qualidades confere um porte político à regulação, enquanto um modo de regulação bastante geral conjuga-se com o movimento liberal da construção europeia. As implicações de tal governança ultrapassam a escolha das características técnicas dos produtos: elas concernem a maneira pela qual são compreendidas as pessoas, as coisas e as suas relações, às quais são atribuídos 
direitos e responsabilidades, assim como oferecem ajuda, mutualidade e solidariedade. Não se trata somente de estandardizar os objetos ou os atos, com a finalidade de compatibilizá-los para um funcionamento industrial eficaz. O desafio está em garantir uma informação formal enquadrando os lugares contratuais entre os sujeitos individuais e contribuindo também à defesa de direitos.

\section{A informação envolvida numa garantia}

A dimensão política da normalização não saberia se reduzir a restrições regulamentarias entre outras. Essa concepção das normas passa por alto em grande parte da atividade normalizadora nas suas relações com a informação. A pesquisa que realizamos sobre a variedade dos lugares de normatividade das normas e a confrontação com outras abordagens da normalização e da metrologia, nos conduzem, no fim do percurso, a reconhecer as implicações políticas menos visíveis imediatamente, mas que são, definitivamente, mais importantes. Elas seguram o modo de envolvimento que sustenta o dispositivo de normalização e as garantias que o instauram.

Pelas capacidades atribuídas aos seres agenciados, cada regime de envolvimento contém uma inquietação própria que o caracteriza: estabelecendo aquilo em que é possível contar, oferece um primeiro porto seguro. A interrogação sobre a pertinência dos conhecimentos que permanecem, ordinariamente, centrados demais no sentido ${ }^{8}$, a racionalização ou as inferências devem prolongar-se numa perspectiva pragmática sobre a garantia. O pragmatismo de Dewey contribuiu a circunscrever os conhecimentos na ação ${ }^{9}$. Notemos, por enquanto, que a sua figura de referência, a enquete (inquiry), aparenta resolver um problema que, formalizado, poderá guiar o programa de inteligência artificial e o cognitivismo. Um programa contemporâneo de política pragmática e moral requer uma abordagem da experiência menos limitada ao formato de "problema" e mais aberta aos envolvimentos diversos cujas conveniências não são redutíveis a esse formato. Dewey (1929) adianta pertinentemente a tensão que pesa na experiência ordinária, entre a pesquisa de "segurança" e a incerteza. Cada um dos termos de segurança e de incerteza demanda ainda assim ser aprofundado e especificado segundo os regimes de envolvimento. Sua relação não parece tão antagônica quando se percebe que a incerteza não é uma categoria principal, ela depende de um quadro de controle que governa uma inquietude. A noção de "antecipação" utilizada pela ação racional do ator econômico, ou o de "espera" que sustenta

8 Sobre esta questão, ver a releitura crítica feita por Conein da "abordagem interpretativa" e do tratamento sensato da relação entre ambiente e os seus objetos (Conein, 1997).

9 A circunscrição no sentido da ação marca a herança do pragmatismo de Dewey e Mead na sociologia, particularmente no interacionismo. Cf. a entrevista de Anselm Strauss com Isabelle Baszanger (Strauss, 1992 p. 40). 
com frequência a definição das convenções, exige que elas sejam substituídas neste quadro: a incerteza depende de uma atenção seletiva aos feedbacks da realidade que caracterizam um regime de envolvimento.

Assim, o sistema de informação das estatísticas sociais que evocamos precedentemente participa dos modos de garantia solidária e da responsabilização coletiva assinalando um compromisso entre as grandezas civica e industrial de justificação. A compreensão dos seres humanos segundo as qualificações coletivas de estados ou de necessidades convêm para atingir as populações, principalmente as "populações em risco", sobre as quais devem constar medidas de Estado. A "revolução cognitiva" promove compreensões diferentes dos seres humanos a partir das suas caracterizações de uma individualidade equipada por diversos "mapas" registrando as suas propriedades (dos mapas de competências à medicina preditiva). Ela se assenta no regime de envolvimento da projeção que se presta à atribuição da vontade livre e à imputação de responsabilidade. Essas compreensões sustentam figuras morais e políticas de responsabilização individual e de seguros de garantia bem diferentes dos precedentes.

\section{O pluralismo crítico sobre o qual se abre a diversidade dos formatos de informação}

O desvio pela normalização e metrologia das coisas nos fez ver os limites das tentativas sucessivas de redução às propriedades físico-químicas e depois às funcionalidades compatíveis com um envolvimento na projeção. Foge dessa redução o modo do envolvimento familiar que rege as acomodações de proximidade e as inovações de uso afastadas da figura do "consumidor" (inclusive quando as teorias econômicas nos mostram um consumidor que descobre as propriedades de um bem enquanto o utiliza), do mesmo modo que ele governa as habilidades de experiência no trabalho que não encontram lugar do modelo da projeção a ser executada (THÉVENOT, 1995b). Neste regime de envolvimento familiar, não há imputação de responsabilidade possível a qualquer ser humano ou a qualquer peça de equipamento, pois a responsabilidade é distribuída num sentido forte, no conjunto de agentes implicados (THÉVENOT, 1993b) ${ }^{10}$. A garantia não pode repousar nesta imputação individualizada, ela passa pela dinâmica de acomodamento mútuo que caracteriza este regime do próximo (régime du proche) e o gênero de segurança que suscita. O paradoxo da governança pelas normas que vemos hoje no auge do seu

10 A atividade de comercialização pode, ela mesma, se fazer objeto de uma análise similar. A normalização e a relação com o leque de coisas que tendem a operar uma redução das formas de envolvimentos fidelizados entre comprador e vendedor, via circuitos de distribuição colocando em frente o "conselho". Para uma análise da variedade das formas de julgamento e dos riscos de redução num mercado de serviços, o mercado do trabalho, ver Eymard-Duvernay e Marchal (1997). Para uma elaboração destas diferenças numa oposição entre uma “organização planificada" do trabalho e "organização distribuída”, ver Dodier (1995). 
florescimento está em que ela se desenvolve numa economia fundamentada amplamente nesse regime familiar, tanto para as inovações dos usos que dão lugar à criação de novos produtos mercantis, como para as inovações de trabalho e organização. A gestão da flexibilidade apela amplamente para dinâmicas que se inscrevem nesse regime, inclusive quando os sistemas de informação que servem para a certificação das qualidades das pessoas e das coisas emergem evidentemente de outros formatos de informação e regimes de garantia (THÉVENOT, 1993b). Observa-se então o risco de absorção de diversos regimes numa noção unitária de "qualidade" que a fará perder de vista as exigências de um pluralismo crítico ao proveito de uma informação uniforme dominada por um standard de cognição.

\section{REFERÊNCIAS}

1. AFFICHARD, J. (ed.). Pour une histoire de la statistique. Paris, INSEE; Economica, 1987. (t. 2).

2. AGRE, P. E. Surveillance and Capture: Two Models of Privacy. The Information Society, v.10, n. 2, p.101-127, 1994.

3. AURAY, N. Ironie et solidarité dans un milieu technicisé. Les défis contre les protections dans les collectifs de hackers. In: CONEIN, B.; THEVENOT, L. (ed.). Cognition et information en société, Paris: Les Éditions de l'EHESS, 1997. p.177-201. (Raisons pratiques 8).

4. BECKER, H. Les mondes de l'art. Paris: Flammarion, 1988.

5. BESSY, C.; CHATEAURAYNAUD, F. Experts et faussaires: pour une sociologie de la perception. Paris: Métailié. 1995.

6. BOLTANSKI, L. L'amour et la justice comme compétences. Paris: Métailié. 1990.

7. BOLTANSKI, L. La souffrance à distance: Morale humanitaire, médias et politique. Paris: Métailié, 1993.

8. BOLTANSKI, L.; THEVENOT, L. De la justification: Les économies de la grandeur. Paris: Gallimard, 1991.

9. BOWKER, G.; STAR, S. L. Knowledge and infrastructure in international information management; problems of classification and coding. In: BUD-FRIERMAN, L. (ed.). Information Acumen: The Understanding and Use of Knowledge in Modern Business. London: Routledge, 1994.

10. CALLON, M.; LAW, J. La proto-histoire d'un laboratoire ou le difficile mariage de la 
science et de l'économie. Cahiers du CRISES, n. 32, p. 1-34, 1989.

11. CASABIANCA, F.; VALCESCHINI, E. La qualité dans l'agro-alimentaire: émergence d'un champ de recherches. AIP «Construction sociale de la qualité», INRA - SESAMES.

12. CICOUREL, A. Cognitive Sociology: Language and Meaning in Social Interaction. New York: Free Press, 1974.

13. CICOUREL, A. The Integration of Distributed Knowledge in Collaborative Medical Diagnosis. In: J. GALEGHER, R. E.; KRAUT, C. E.; EGIDO, C. (ed.). Intellectual Teamwork. Social and Technological Foundations of Cooperative Work. Hillsdale, N.J; Hove and London: Lawrence Erlbaum Associates, 1990. p. 221-242.

14. CLAVERIE, E. La description des formes sensibles de la religion en sciences sociales. Archives des Sciences Sociales des Religions, Novembro de 1997.

15. COLLINS, H.; YEARLEY, S. Epistemological Chicken. In: PICKERING, A. Science as Practice and Culture. Chicago: University of Chicago Press, 1992. p. 301-326.

16. COMMISSION EUROPEENNE . Livre blanc sur l'éducation et la formation: enseigner et apprendre, vers la société cognitive. 1995.

17. CONEIN, B. L'action avec les objets. Un autre visage de l'action située? In: CONEIN, B.; THEVENOT, L. (ed.). Cognition et information en société. Paris: Les Éditions de l'EHESS, 1997. p. 25-45. (Raisons pratiques 8).

18. CONEIN, B.; JACOPIN, E. Les objets dans l'espace; la planification dans l'action. In: CONEIN, B. DODIER, N.; THEVENOT, L. (ed.). Les objets dans l'action. Paris: Les Éditions de l'EHESS, 1993. p. 59-84. (Raisons pratiques 5).

19. CONEIN, B., JACOPIN, E. Action située et cognition; le savoir en place. Sociologie du Travail, v.XXXVI, n. 4, p. 475-500, 1994.

20. DAVID, P. Les standards des technologies de l'information, les normes de communication et l'Etat : un problème de biens publics. In: ORLEAN, A. (ed.). Analyse économique des conventions. Paris, PUF, 1994. p. 249-278.

21. DE BANDT, J.; GADREY, J. (ed.). Relations de service, marchés de service. Paris: CNRS éditions, 1994.

22. DEROUET, J.-L. Ecole et justice: De l'égalité des chances aux compromis locaux. Paris: Métailié, 1992.

23. DE SAINTE MARIE, C.; PROST, J.-A.; CASABIANCA, F.; CASALTA, E. La construction sociale de la qualité. Enjeux autour de l'Appellation «Brocciu Corse». In: NICOLAS, F.; E. Valceschini (ed.). Agro-alimentaire: une économie de la qualité. Paris: INRA- Economica, 1995. p. 185-198.

24. DESROSIERES, A. La politique des grands nombres: Histoire de la raison statistique. 
Paris: La Découverte, 1993.

25. DESROSIERES, A.; THEVENOT, L. Les catégories socioprofessionnelles. Paris: La Découverte, 1988.

26. DODIER, N. L'expertise médicale: Essai de sociologie sur l'exercice du jugement. Paris: Métailié, 1993.

27. DODIER, N. Les hommes et les machines: La conscience collective dans les sociétés contemporaines. Paris : Métailié, 1995.

28. EYMARD-DUVERNAY, F.; MARCHAL, E. Façons de recruter: Le jugement des compétences sur le marché du travail. Paris : Centre d'Etudes de l'Emploi \& Ed. Metailié, 1997.

29. FAGUER, J.-P.; GOLLAC, M.Ordinateur universel ou personnel ? Clarté et ambiguïté dans la définition des techniques. In: CONEIN, B.; THEVENOT, L. (ed.). Cognition et information en société. Paris: Les Éditions de 1'EHESS, 1997. p. 97-121. (Raisons Pratiques 8).

30. FORAY, D. Standardisation et concurrence; des relations ambivalentes. Revue d'Economie Industrielle, n. 63, 1993.

31. FRIEDBERG, E. Le Pouvoir et la Règle: Dynamique de l'action organisée. Paris: Seuil, 1993.

32. GASSER, L. Social Conceptions of Knowledge and Action: DAI Foundations and Open Systems Semantics. Artificial Intelligence, v. 47, n. 1-3, p. 107-138, 1991.

33. HUNOUT, P. L'évaluation et la classification des emplois. CEREQ, Documents de travail, n. 29, 1987.

34. HUTCHINS, E. Comment le 'cockpit' se souvient des vitesses. Travail et cognition, v. XXXVI, n. 4, p. 451-4473, 1994.

35. KESSOUS, E. Le marché et la sécurité: La prévention des risques et la normalisation des qualités dans le marché unique européen. 1997. $556 \mathrm{f}$. Thèse (doctorat d'Economie des Institutions sous la direction de L. Thévenot). - EHESS, Paris, 1997.

36. LAFAYE, C.; THEVENOT, L. Unejustification écologique? Conflits dans l'aménagement de la nature. Revue Française de Sociologie, v. 34, n. 4, p. 495-524, 1993.

37. LATOUR, B. Les anges ne font pas de bons instruments scientifiques. In: La clé de Berlin et autres leçons d'un amateur de sciences. Paris: La Découverte, 1993.

38. LATOUR, B. La science en action : Introduction à la sociologie des sciences. Paris: Gallimard, 1995.

39. LAW, J. Organizing Modernity. Oxford: Blackwell, 1994. 
40. MALLARD, A. Les instruments dans la coordination de l'action: pratique technique, métrologie, instrument scientifique. 1996. 658 f. Thèse (Doctorat de Socio-économie sous la direction de Bruno Latour) - École Nationale des Mines de Paris, 1996.

41. MEYERS, P. A Theory of Power: Political, not Metaphysical. Ann Arbor: UMI, 1989.

42. MORAND, F. Quelles conventions pour protégéer le patrimoine rural en le modernisant, contribution aux troisièmes rencontres «Économie des Institutions», organisées par Gilles Allaire et Robert Boyer, Dourdan, 4-7 décembre, 1996.

43. MORAND, F. Regards croisés sur la Buèges: Prendre en compte les représentations d'acteurs dans l'accompagnement de la transition vers l'agro-tourisme. Montpellier: INRA (SAD-LECSA), 1997.93 p.

44. MOULIERAC, F. Désaccords sur la défaillance d'objets techniques. Interactions au Service Après-Vente entre utilisateurs et réparateurs, mémoire de DEA de sociologie de l'EHESS, sous la direction de L. Thévenot, 1993. 127 p.

45. NORMAN, D. A. Les artefacts cognitifs. In: CONEIN, B.; DODIER, N.; THEVENOT, L. (éd.). Les objets dans l'action. Paris: Les Éditions de l'EHESS, 1993. p. 15-34. (Raisons Pratiques 4).

46. NORMAND, R. De la norme aux territoires. L'enjeu d'une définition de la qualité autour du mobilier scolaire», contribution aux troisièmes rencontres «Économie des Institutions», organisées par Gilles Allaire et Robert Boyer, Dourdan, 4-7 décembre, 1996.

47. NORMAND, R. La délagation aux objets dans le mobilier scolaire. In: DEROUET, J.-L. (ed.). L'école dans plusieurs mondes. Paris: INRP, 1997.

48. O'CONNEL, J. Metrology: The Creation of Universality by the Circulation of Particulars. Social Studies of Science, v.23, p. 123-173, 1993.

49. PARADEISE, C. Acteurs et institutions: la dynamique des marchés du travail. Sociologie du Travail, v. XXX, n.1, p. 79-105, 1988.

50. PEZET, E. La négociation des classifications dans la métallurgie 1968-1975: contexte, acteurs et méthode d'une innovation sociale, mémoire de DEA d'histoire, mention science des organisations, sous la direction de P. Fridenson, EHESS, 1997. 151 p.

51. PICKERING, A. The Mangle of Practice. Chicago: The University of Chicago Press, 1995.

52. STAR, S. L. Power, technology and the phenomenology of conventions: on being allergic to onions. In: LAW, J. (ed.). A Sociology of Monsters? Power, Technology and the Modern World. Oxford: Basil Blackwell, 1991. p. 27-57. (Sociological Review Monograph, n. 38).

53. STAR, S. L.; GRIESEMER, J. R. Institutional Ecology, 'Translations', and Boundary 
Objects: Amateurs and Professionals in Berkeleys's Musemum of Vertebrate Zoology, 1907-1939. Social Studies of Science, v. 19, n. 3, p. 387-420, 1989.

54. STAR, S. L.; BOWKER, G. Problèmes de classification et de codage dans la gestion internationale de l'information. In: CONEIN, B.; THEVENOT, L. (ed.). Cognition et information en société. Paris: Les Éditions de l'EHESS, 1997.

55. STRAUSS, A. La trame de la négociation: Sociologie qualitative et interactionnisme. Paris : L'Harmattan, 1992.

56. SYLVANDER, B. Conventions de qualité, concurrence et coopération. Le cas du 'label rouge' dans la filière volailles. In: ALLAIRE, G.; BOYER, R. (ed.). La grande transformation de l'agriculture: lectures conventionnalistes et régulationnistes. Paris : INRA-Economica, 1995. p.73-96.

57. THÉVENOT, L. Les investissements de forme. In: THEVENOT, L. (ed.). Conventions économiques. Paris: PUF, 1986. p. 21-71. (Cahiers du Centre d'Etudes de 1'Emploi).

58. THÉVENOT, L. Economie et politique de l'entreprise; économies de l'efficacité et de la confiance. In: BOLTANSKI, L.; THEVENOT, L. (ed.). Justesse et justice dans le travail. Paris: PUF, 1989. p. 135-207. (Cahiers du Centre d'Etudes de 1'Emploi).

59. THÉVENOT, L. La politique des statistiques: les origines sociales des enquêtes de mobilité sociale. Annales E.S.C., n. 6, p. 1275-1300, 1990a.

60. THÉVENOT, L. L'action qui convient. In: PHARO, P.; QUERE, L. (ed.). Les formes de l'action. Paris: Les Éditions de l'EHESS, 1990b. p. 39-69. (Raisons Pratiques 1).

61. THÉVENOT, L. Jugements ordinaires et jugement de droit. Annales ESC., n. 6, p. 12791299, 1992.

62. THÉVENOT, L. Essai sur les objets usuels : propriétés, fonctions, usages. In: CONEIN, B.; DODIER, N. ; THEVENOT, L. (ed.). Les objets dans l'action. Paris : Les Éditions de l'EHESS, 1993a. p. 85-111. (Raisons Pratiques 4).

63. THÉVENOT, L. 1993b. «Le savoir au travail. Attribution et distribution des compétences selon les régimes pragmatiques», communication au colloque «Limites de la rationalité et constitution du collectif», Cerisy, publié dans B. Reynaud (ed.), 1997, Les limites de la rationalité, tome 2, Les Figures du Collectif, Paris, La Découverte, p. 299-321.

64. THÉVENOT, L. Statistique et politique: la normalité du collectif. Politix, n. 25, p. 5-20, 1994a.

65. THÉVENOT, L. Le régime de familiarité; des choses en personnes. Genèses, n.17, p. $72-101,1994 b$.

66. THÉVENOT, L. Objets en société. Suivre les choses dans tous leurs états. Alliage, n. 21, p. 74-87, 1994c. 
67. THÉVENOT, L. Des marchés aux normes. In: ALLAIRE, G.; BOYER, R. (ed.). La grande transformation de l'agriculture: lectures conventionnalistes et régulationnistes. Paris: INRA-Economica, 1995a. p. 33-51.

68. THÉVENOT, L. L'action en plan. Sociologie du Travail, v. XXXVII, n. 3, p. 411-434, $1995 b$.

69. THÉVENOT, L. Emotions et évaluations dans les coordinations publiques. In: PAPERMAN, P.; R. OGIEN, R. (ed.). La couleur des pensées: emotions, sentiments, intentions. Paris: Les Éditions de l'EHESS, 1995c. p. 145-174. (Raisons Pratiques 4).

70. THÉVENOT, L. Mettre en valeur la nature; disputes autour d'aménagements de la nature en France et aux Etats-Unis. Autres Temps: Cahiers d'éthique sociale et politique, $\mathrm{n}$. 49 , p. 27-50, 1996 a.

71. THÉVENOT, L. "Pragmatic regimes and the commerce with things; from personal familiarization to public 'qualifications'. In: KNORR-CETINA, K., Schatzki, T. SAVIGNY Eike v. (eds.), The Practice Turn in Contemporary Theory, London, Routledge, 2001. p.56-73.

72. THÉVENOT, L. (avec la collaboration de E. Kessous et R. Normand). Coordinations économiques par des normes de qualité: approches économiques et juridiques de la normalisation. Rapport d'activité subventionné par l'aide du Ministère de la Recherche $\mathrm{n}^{\circ}$ 92D0546 du 12 novembre 1992. Paris: Institut International de Paris - La Défense, 1996c. 291 p. (v. 3).

73. THÉVENOT, L. La normalisation dans les relations économiques. In: CASABIANCA, F.; VALCESCHINI, E. La qualité dans l'agro-alimentaire: émergence d'un champ de recherches; AIP “Construction sociale de la qualité”. Paris: INRA - SESAMES, 1996d.

74. THÉVENOT, L. 1998. Pragmatiques de la connaissance. In: BORZEIX, A.; BOUVIER, A.; PHARO, P. (ed.). Sociologie et Cognition. CNRS EDITIONS, 1998.

75. DE VIRVILLE, M. (sous la présidence de). 1996. "Donner un nouvel élan à la formation professionnelle", relatório da missão encomendada pelo Ministro do Trabalho francês, do dialogo social e da participação, 1996.

76. WAGNER, P. Liberté et discipline: les deux crises de la modernité. Paris: Métailié, 1996.

77. WISSLER, A. Les jugements dans l'octroi de crédit. In: BOLTANSKI, L. THEVENOT, L. (ed.), Justesse et justice dans le travail. Paris: PUF, 1989. p. 67-119. (Cahiers du Centre d'Etudes de l'Emploi, n. 33).

\section{Referências da edição e atualização}

1. BREVIGLIERI, M. The Guarenteed City. The Ruin of Urban Criticism? In: RESENDE, 
J. M.; MARTINS, A. C.; BREVIGLIERI, M.; DELAUNAY, C. (ed.). The Challenges of Communication in a Context of Crisis. Newcastle upon Tyne: Cambridge Scholars Publishing, 2018. p. 200-227.

2. BRUNNSON, N.; JACOBSON, B. A world of standards. Oxford: Oxford University Press, 2000.

3. CHEYNS, E.; THÉVENOT, L. Government by Certification Standards: The Consent and Complaints of Affected Communities. In: La Revue des droits de 1'homme, 16,

4. $2019 \mathrm{~b}$.

5. DASTON, L. J.; GALISON, P. Objectivity. New York: Zone Books, 2007.

6. DESROSIERES, L.; THEVENOT, L. Les mots et les chiffres: les nomenclatures socioprofessionnelles. Economie et Statistique, n. 110, p. 49-65, 1979.

7. GARSTEN, C.; JACOBSSON, K. Post-Political Forms of Regulation: Soft Power and Post-Political Visions in Global Governance. Critical Sociology, v. 39, n. 3, p. 421437 , 2013.

8. GORUR, R. Towards a Sociology of Measurement in Education Policy. European Educational Research Journal, v. 13, n. 1, p. 58-72, 2014.

9. LANDRI, P. Governing by Standards: The Fabrication of Austerity in the Italian Education System. Education Inquiry, v. 5, n. 1, p. 25 41, 2014.

10. LANDRI, P. Standards and Standardisation in European Politics of Education. In: NORMAND, R.; DEROUET, J.-L. (ed.). A European Politics of Education: Perspectives from Sociology, Policy Studies and Politics. London: Routledge, 2016. p. 13-30.

11. LAWN, M. Standardizing the European Education Policy Space. European Educational Research Journal, v. 10, n. 2, p. 259-272, 2011.

12. RESENDE, J. M.; VIERA, M. M. (ed.). The Crisis of Schooling? Learning, Knowledge and Competencies in Modern Societies. Newcastle upon Tyne: Cambridge Scholars Publishing, 2009.

13. RESENDE, J. M.; MARTINS, A. C. (ed.). The Making of the Common in Social Relations. Newcastle upon Tyne: Cambridge Scholars Publishing, 2015.

14. RESENDE, J. M.; MARTINS, A. C., BREVIGLIERI, M.; DELAUNAY, C. (ed.). The Challenges of Communication in a Context of Crisis. Newcastle upon Tyne: Cambridge Scholars Publishing, 2018.

15. RESENDE, J. M.; GOUVEIA, L.; BEIRANTE, D. Relational Challenges in the face of School Governance by Standards: Mistakes, Disagreements and Criticisms. In: RESENDE, J. M.; MARTINS, A. C.; BREVIGLIERI, M.; DELAUNAY, C. (ed.). 
The Challenges of Communication in a Context of Crisis. Newcastle upon Tyne: Cambridge Scholars Publishing, 2018. p. 54-82.

16. STAVO-DEBAUGE, J. Mobilising Statistical Powers for Action against Discriminations: the Case of the United Kingdom. International Social Science Journal, n. 183, p. 43$55,2005$.

17. THÉVENOT, L. Une jeunesse difficile: Les fonctions sociales du flou et de la rigueur dans les classements. Actes de la recherche en sciences sociales, n. 26-27, p. 3-18, 1979.

18. THÉVENOT, L. L'économie du codage social. Critiques de l'Economie Politique, n. 23-24, p.188-222, 1983.

19. THÉVENOT, L. Rules and implements: investment in forms. Social Science Information, v.23, n. 1, p. 1-45, 1984.

20. THÉVENOT, L. The Plurality of Cognitive Formats and Engagements: Moving between the Familiar and the Public. European Journal of Social Theory, v. 10, n. 3, p. 413427, 2007.

21. THÉVENOT, L. Governing Life by Standards: A View from Engagements. Social Studies of Science, v. 39, n. 5, p. 793-813, 2009.

22. THÉVENOT, L. Conventions for Measuring and Questioning Policies: The Case of 50 years of Policies Evaluations through a Statistical Survey. Historical Social Research, Special issue edited by Rainer Diaz-Bone \& Robert Salais on Conventions and Institutions from a Historical Perspective (translation by Susan Taponier), v. 36, n. 4, p. 192-217, 2011.

23. THÉVENOT, L. Certifying the World: Power Infrastructures and Practices in Economies of Conventional Forms. In: ASPERS, P.; DODD, N. (ed.). Re-Imagining Economic Sociology. Oxford: Oxford University Press, 2015f. p. 195-223.

24. THÉVENOT, L. From Codage social to Economie des conventions: A Thirty Years Perspective on the Analysis of Qualification and Quantification Investments. Historical Social Research, Special issue edited by Rainer Diaz-Bone \& Emmanuel Didier on Conventions and quantification in economy, politics and statistics - historical perspectives, v. 41, n. 2, p. 96-117, 2016.

25. THÉVENOT, L. Measure for Measure: Politics of Quantifying Individuals to Govern them. Historical Social Research, special issue on Governing by numbers: Key indicators and the politics of expectations, edited by Walter Bartl, Christian Papilloud, Audrey Terracher-Lipinski, v. 44, n. 2, p. X-X, 2019 b.

26. THÉVENOT, L. A New Calculable Global World in the Making: Governing through Transnational Certification Standards. In: MENNICKEN, A.; SALAIS, R. (ed.). The New Politics of Numbers: Quantification, Administrative Capacity and Democracy. 
London: Palgrave Macmillan, 2019c.

\section{Outras referências do autor}

1. THÉVENOT, L. Des marchés aux normes. In: ALLAIRE, G.; BOYER, R. (ed.). La grande transformation de l'agriculture: lectures conventionnalistes et régulationnistes. Paris: INRA-Economica, 1995c. p. 33-51.

2. THÉVENOT, L. La mise en place d'un gouvernement par les normes à l'échelle européenne. In: DEROUET, J-L.; NORMAND, R. (ed.). L'Europe de l'éducation: entre management et politique. Lyon: Institut National de la Recherche Pédagogique et Ecole Supérieure de 1'Education Nationale, 2007d. p. 55-62.

3. THÉVENOT, L. Governing Life by Standards: A View from Engagements. Social Studies of Science, v.39, n. 5, p. 793-813, 2009c.

4. THÉVENOT, L. Certifying the world. Power infrastructures and practices in economies of conventional forms. In: ASPERS, P.; DODD, N. (ed.). Re-Imagining Economic Sociology. Oxford: Oxford University Press, 2015f. p. 195-223.

5. THÉVENOT, L. From Codage social to Economie des conventions: A Thirty Years Perspective on the Analysis of Qualification and Quantification Investments. Historical Social Research, Special issue edited by Rainer Diaz-Bone \& Emmanuel Didier on Conventions and quantification in economy, politics and statistics - historical perspectives, v. 41, n. 2, p. 96-117, $2016 \mathrm{~d}$.

6. THÉVENOT, L. Droits et biens pris en compte par les engagements volontaires d'entreprises dans des standards internationaux. La 'sustainable palm oil' certification au regard des plus défavorisés. In: JEAMMAUD, A.; Le FRIANT, M.; LOKIEC, P.; WOLMARK, C. (eds.). A droit ouvert. Paris Dalloz, 2018b. p. 929-945.

7. CHEYNS, E.; THÉVENOT, L. Le gouvernement par standards de certification consentement et plaintes des communautés affectées. La Revue des droits de l'homme, n. 16, 2019a.

8. THÉVENOT, L. Measure for Measure: Politics of Quantifying Individuals to Govern Them. Historical Social Research, v. 44, n. 2, p. 44-76. $2019 \mathrm{~b}$.

9. THÉVENOT, L. A New Calculable Global World in The Making: Governing through Transnational Certification Standards. In: MENNICKEN, A.; SALAIS, R. (ed.). The New Politics of Numbers: Quantification, Administrative Capacity and Democracy. London: Palgrave Macmillan, 2020c. 


\section{Laurent Thévenot}

Professor emérito (Diretor de estudos) na École des Hautes Etudes en Sciences Sociales. ID ORCID: https://orcid.org/0000-0002-4317-0419. E-mail: laurent.thevenot@ehess.fr. Colaboração: Redação, Pesquisa, Revisão.

\section{Daniela Velásquez Peláez}

Doutoranda do Programa de Pós-Graduação em Antropologia da Universidade Federal Fluminense. Mestre em Antropologia pela Universidade Federal Fluminense (2016). Pesquisadora do Núcleo Fluminense de Estudos e Pesquisa, e do Instituto Nacional de Administração de Conflitos. ID ORCID: https://orcid.org/0000-0003-2062-7655. E-mail: dann. velasquez@gmail.com. Colaboração: Tradução, Revisão. 